\title{
Effects of Addition of Carbon Dioxide on Thermal Characteristics in Oxygen-Enriched Hydrogen Flame*
}

\author{
Chang Yeop LEE**, Seung Wook BAEK ${ }^{* *}$ and Joon Won CHOI**
}

\begin{abstract}
An experimental study has been conducted to evaluate the effects of $\mathrm{CO}_{2}$ addition on thermal behavior in oxygen-enriched hydrogen flame. Experiments were performed on flames stabilized by a co-flow swirl burner, which was mounted on top of the furnace. Several different oxidizer compositions were prepared by volumetrically replacing $\mathrm{N}_{2}$ by $\mathrm{CO}_{2}$. In a steady state, the total as well as radiative heat flux from the flame to the wall of furnace has been measured using a heat flux meter. Temperature distribution in furnace has been also measured and compared. By increasing $\mathrm{CO}_{2}$ proportion in the oxidizer, the convection became to play a more significant role rather than radiation due to heat blockage effect. Overall temperature in the furnace was seen to decrease, while the total heat flux has increased.
\end{abstract}

Key Words: Hydrogen Combustion, Oxygen-Enriched, $\mathrm{CO}_{2}$, Heat Transfer, Radiation, Heat Flux Meter, $\mathrm{NO}_{\mathrm{x}}$

\section{Introduction}

Nowadays, research on hydrogen gas has been very active since it is regarded as an alternative and clean energy. Many researchers has investigated its use as a fuel in order to replace the fossil fuel, for its complete burning in air only produces $\mathrm{H}_{2} \mathrm{O}$ and $\mathrm{N}_{2}$. Its basic combustion characteristics have been examined by Melvin ${ }^{(1)}$. The effect of swirl number and gas velocity on hydrogen flame height has been studied by Sano et al. ${ }^{(2)}$ On the other hand, Suzuki et al. considered the effects of additives on $\mathrm{NO}_{x}$ emission from hydrogen flame ${ }^{(3)}$.

Sometimes, oxygen-enriched combustion was introduced to raise combustion efficiency by increasing oxygen ratio in oxidizer. Oxygen-enriched combustion induces a higher flame temperature and increases the heat transfer efficiency by reducing a diluent gas of $\mathrm{N}_{2}$ in air. It is now commercially used in the area of glass and steel production in which an environment of high temperature and radiative heat transfer is required.

Theoretically, the waste energy, that is used to heat up nitrogen in air, would be appropriated to useful energy by replacing air with oxygen. As the oxygen concentration increases, the flammability limit is also further extended

* Received 11th November, 2004 (No. 04-5176)

** Division of Aerospace Engineering, Department of Mechanical Engineering, Korea Advanced Institute of Science and Technology, 373-1 Guseong-dong, Yuseong-gu, Daejeon 305-701, Korea. E-mail: swbaek@kaist.ac.kr to fuel-lean side. When pure oxygen is substituted into air, the concentrations of $\mathrm{CO}_{2}$ and $\mathrm{H}_{2} \mathrm{O}$ become higher, which are very active in radiation so that the flame emissivity would be enhanced ${ }^{(4)}$. However, since the flame temperature is too high, sometimes its temperature needs to be controlled by retrieving the carbon dioxide in product gas and mixing it with reactants in regenerative way. Its effect on flame radiation in oxygen-enhanced combustion is discussed by Baukal and Gebhart ${ }^{(5)}$. On the other hand, some researchers have studied the effects of $\mathrm{CO}_{2}$ as an additive to suppress $\mathrm{NO}_{\mathrm{x}}$ for various fuel-air combustions ${ }^{(6),(7)}$.

In this paper, the effect of addition of $\mathrm{CO}_{2}$ on radiative as well as convective heat transfer has been experimentally elucidated in oxygen-enriched hydrogen flame while keeping the equivalence ratio fixed by systematically controlling a substitution of $\mathrm{CO}_{2}$ into $\mathrm{N}_{2}$ in air.

\section{Experimental Setup}

\subsection{Experimental apparatus}

A laboratory size of experimental furnace with burner was designed and fabricated. The furnace was verticallydownward installed to avoid full three dimensionality of the flame shape. Various gases such as hydrogen, air, oxygen and carbon dioxide, used in experiment were provided through volumetric flow meters. The signals from thermocouple and total as well as radiative heat flux meter were recorded on computer with an A/D converter board. The overall experimental setup is shown in Fig. 1. 


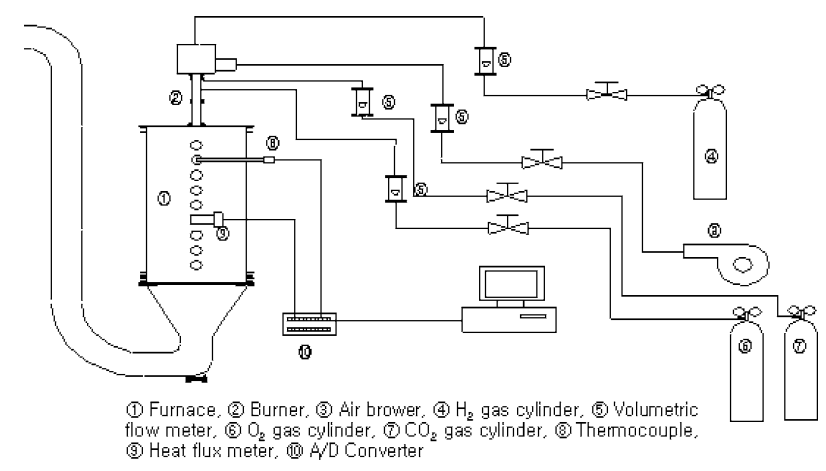

Fig. 1 Experimental set up

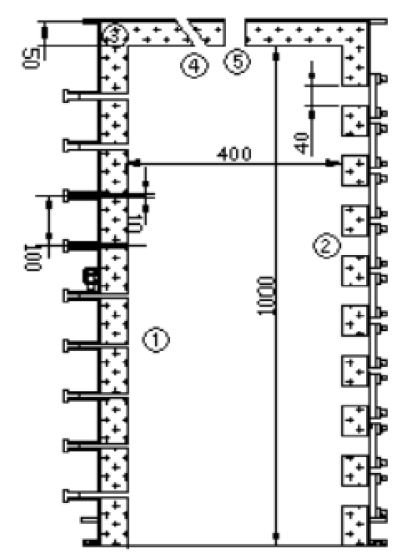

(1) Temperature measuring hole, (2) Heat flux measuring hole, 9 Insulation, (4) Hole for an igniter, (5) Bumer installation hole

Fig. 2 Detailed drawing of furnace

\subsubsection{Furnace As shown in Fig. 2, a cylindrical} type of furnace has been used for experiment. Its diameter is $0.5 \mathrm{~m}$ and height is $1.0 \mathrm{~m}$. On the surface of furnace nine ports of two different sizes were drilled to accommodate heat flux meters that are used for measuring total as well as radiative heat flux at the wall. Thermocouples were also inserted through these ports to assess gas temperature in the furnace as shown in Fig. 2. Nine holes of $2 \mathrm{~mm}$ diameter were also made to measure the inner wall surface temperature distribution on furnace. The Cerakwool was installed for thermal insulation inside the furnace.

2.1.2 Burner A co-annular type burner was constructed to generate hydrogen diffusion flame as seen in Fig. 3. At the tip of outer annulus of the burner is installed a swirler to stabilize flame. Outer pipe diameter for supplying oxidizer and carbon dioxide is $30 \mathrm{~mm}$. Inner diameter for hydrogen is $18 \mathrm{~mm}$. When carbon dioxide is added to oxidizer, a premixing-chamber is used to ensure homogeneous mixing and then supplied through outer pipe. A port for igniter is located on the inlet side of burner so that it is possible to light a fire without opening and closing upper portion of the furnace.

2.1.3 Swirler A swirler is located at the tip of outer annulus to enhance mixing rate of the oxidizer. The

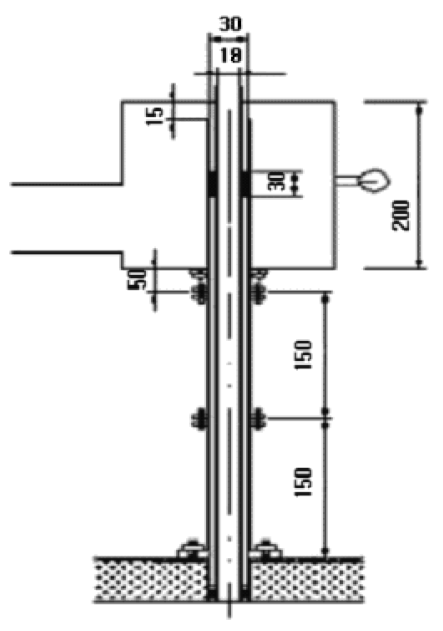

Fig. 3 Detailed drawing of burner

swirler used here is of guide vane type with vane angle of 30 degrees. Following formula has been used to compute the swirl number ${ }^{(8)}$.

$$
S=\frac{2}{3}\left[\frac{1-\left(d_{h} / d\right)^{3}}{1-\left(d_{h} / d\right)^{2}}\right] \tan \theta
$$

where, $d$ : inner diameter of the swirler.

$d_{h}$ : hub diameter of the swirler.

$\theta$ : vane angle of the swirler.

\subsection{Measurement accessories}

Heat flux meters were used to check the heat transfer to the wall. These are commercial products and calibration graphs were supplied from the manufacture company.

2.2.1 Thermocouple In order to measure the temperature, two types of thermocouple were used. While K-type thermocouple was used for surface temperature of the furnace, exposed R-type thermocouple was used to measure gas temperature distribution in the furnace. Various bead sizes were used to predict real temperature by extrapolating the data to zero bead size ${ }^{(9)}$. Thermocouples were electrically treated for protecting them from oxidation in the flame zone. Temperature in the furnace was scanned at intervals of $1-5 \mathrm{~cm}$ along the radial direction and $10 \mathrm{~cm}$ along the axial direction.

2.2.2 Heat flux meter Commercially available heat flux sensors were used to measure the radiative and total heat transfer to the wall from the gas. It is well known Gardon type of heat flux meter.

2.2.3 Gas analyzing system Environmentally pollutant gases such as $\mathrm{NO}, \mathrm{CO}_{2}, \mathrm{CO}$ and $\mathrm{SO}_{2}$ were measured by gas analyzing system. Because $\mathrm{NO}_{\mathrm{x}}$ sensor was sensitively affected by heat, a water-cooled capturing pipe was used for extracting sample gases. Water vapor was removed by filtering before analysis.

\subsection{Experimental condition}

All the experimental data were retrieved when the thermal condition inside furnace reached steady state.

In this study seven experimental conditions were 
Table 1 Experimental conditions

\begin{tabular}{|c|c|c|c|}
\hline \multicolumn{4}{|c|}{ Oxygen enrichment ratio $(\Omega)=0.4$} \\
\hline CASE & $\mathrm{O}_{2}(\%)$ & $\mathrm{N}_{2}(\%)$ & $\mathrm{CO}_{2}(\%)$ \\
\hline CASE 1 & 40 & 60 & 0 \\
\hline CASE 2 & 40 & 40 & 20 \\
\hline CASE 3 & 40 & 30 & 30 \\
\hline CASE 4 & 40 & 20 & 40 \\
\hline CASE 5 & 40 & 0 & 60 \\
\hline \multicolumn{4}{|c|}{ Oxygen enrichment ratio $(\Omega)=0.5$} \\
\hline CASE & $\mathrm{O}_{2}(\%)$ & $\mathrm{N}_{2}(\%)$ & $\mathrm{CO}_{2}(\%)$ \\
\hline CASE 6 & 50 & 50 & 0 \\
\hline CASE 7 & 50 & 0 & 50 \\
\hline
\end{tabular}

tested. For the fixed oxygen enrichment ratio of 0.4 , there are five different compositions of nitrogen and carbon dioxide. Furthermore, the other two compositions were tested when the oxygen enrichment ratio is 0.5 . The oxygen enrichment ratio $(\Omega)$ is defined as volumetric ratio between $\mathrm{O}_{2}$ and total oxidizer as follows.

$\Omega=$ volume flow rate of $\mathrm{O}_{2}$ in the oxidizer/total volume flow rate of oxidizer

Their detailed experimental compositions are listed in Table 1.

\section{Experimental Results and Discussion}

\subsection{The effect of $\mathrm{CO}_{2}$ on flame characteristic for case of $\Omega=0.4$}

Superficial flame behavior was observed through an observation quartz window. Originally, typical hydrogenair flame is non-luminous and visual radiation is very small as seen in Fig. 4 (a). But when the oxygen enrichment ratio becomes 0.4 without $\mathrm{CO}_{2}$, flame emits more visual radiation so that it shows a brighter and more bluish flame as in Fig. 4 (b). This is because the flame temperature increases when the oxygen concentration is enhanced. When $20 \%$ of carbon dioxide replaces nitrogen gas for the fixed oxygen enrichment ratio of 0.4 , the flame emits further more visual radiation and its color turns into more white-blue as in Fig. 4 (c). This is due to the fact that the carbon dioxide added plays an active role in emitting radiation. Thereafter, even if more carbon dioxide is added, the flame color doesn't make further difference.

\subsection{The effect of $\mathrm{CO}_{2}$ on temperature distribution for case of $\boldsymbol{\Omega}=\mathbf{0 . 4}$}

In order to examine the effect of $\mathrm{CO}_{2}$ on temperature distribution along axial direction, the case 1 , case 3 and case 5 have been selected. The case 1 corresponds to a pure oxygen enhanced combustion for $\Omega=0.4$ without $\mathrm{CO}_{2}$ addition. As shown in Fig. 5, the gas temperature reaches a maximum temperature of $1473^{\circ} \mathrm{C}$ at axial distance of $0.3 \mathrm{~m}$ from inlet. When the nitrogen gas is replaced by $30 \%$ of $\mathrm{CO}_{2}$ (case 3 ), the maximum temperature decreases by $113^{\circ} \mathrm{C}$. When $60 \%$ of $\mathrm{CO}_{2}$ is substituted into all nitrogen gas (case 5), the maximum temperature is

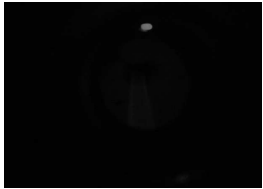

(a)

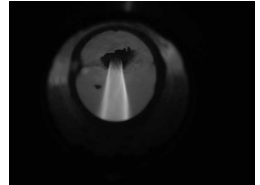

(b)

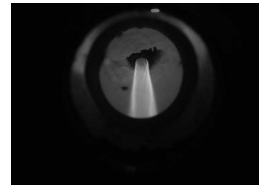

(c)
Fig. 4 Visual flame characteristics

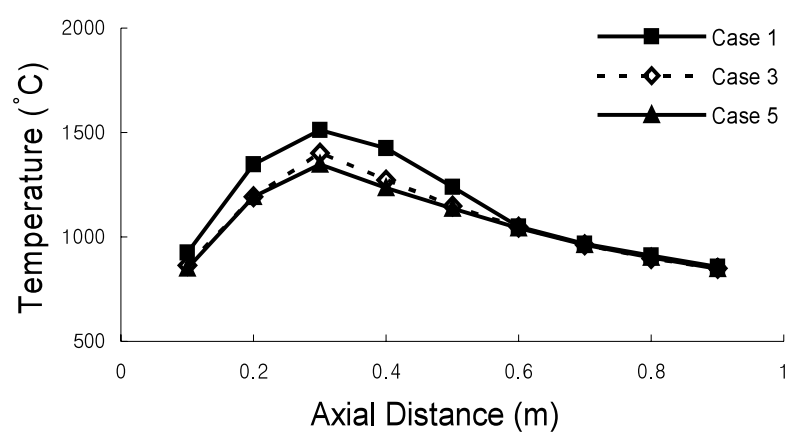

Fig. 5 Axial temperature distribution at the centerline

Table 2 Molar specific heat under constant pressure (unit: $\mathrm{cal} / \mathrm{mol} \cdot \mathrm{K}$ )

\begin{tabular}{|c|c|c|}
\hline Temperature (K) & $\mathrm{CO}_{2}$ & $\mathrm{~N}_{2}$ \\
\hline 300 & 8.896 & 6.961 \\
\hline 600 & 11.310 & 7.196 \\
\hline 900 & 12.667 & 7.670 \\
\hline 1200 & 13.446 & 8.061 \\
\hline 1500 & 13.953 & 8.330 \\
\hline 1800 & 14.269 & 8.512 \\
\hline
\end{tabular}

reduced by $172^{\circ} \mathrm{C}$. In other words, the more $\mathrm{CO}_{2}$ gas is added to the oxidizer, the lower the overall gas temperature in upstream. Especially, the region up to $0.6 \mathrm{~m}$ from the inlet is affected in temperature distribution.

This phenomenon might result from a difference in thermal characteristic between $\mathrm{N}_{2}$ and $\mathrm{CO}_{2}$. Table 2 shows the molar specific heat of $\mathrm{N}_{2}$ and $\mathrm{CO}_{2}{ }^{(10)}$. The molar specific heat for $\mathrm{CO}_{2}$ is bigger than that for $\mathrm{N}_{2}$ and its difference between two gases even gets larger at higher temperature. So when $\mathrm{CO}_{2}$ gas was supplied in place of $\mathrm{N}_{2}$ gas on the same volumetric flow rate, the rate of increase in gas temperature is much reduced. Another reason for the lower gas temperature for more $\mathrm{CO}_{2}$ addition is that the total heat loss to the wall is higher for more $\mathrm{CO}_{2}$ addition as will be observed below.

Finally, there would be a supplementary reason such as chemical effects incurred by $\mathrm{CO}_{2}$ addition as noted by Park et al. and Lee and Park ${ }^{(11),(12)}$. CO is converted from $\mathrm{CO}_{2}$ through the dominant reaction $\mathrm{CO}_{2}+\mathrm{H} \rightarrow \mathrm{CO}+$ $\mathrm{OH}$. The existence of $\mathrm{CO}$ inhibits the most important chain branching reaction, $\mathrm{H}+\mathrm{O}_{2}=\mathrm{O}+\mathrm{OH}$ so that overall reaction rate of fuel decreases and the increase of initial $\mathrm{CO}_{2}$ concentration induces the increase of $\mathrm{CO}$ mole frac- 


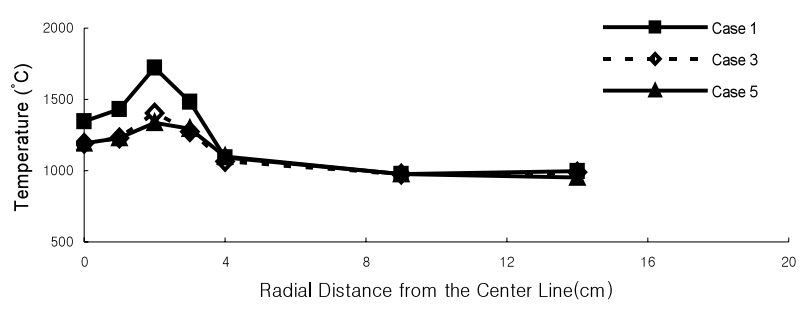

(a) $z=0.2 \mathrm{~m}$

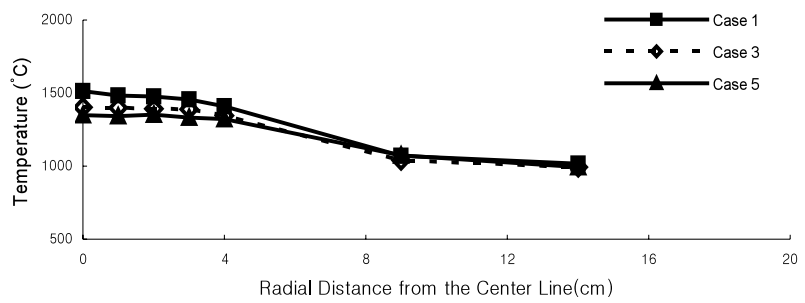

(b) $z=0.3 \mathrm{~m}$

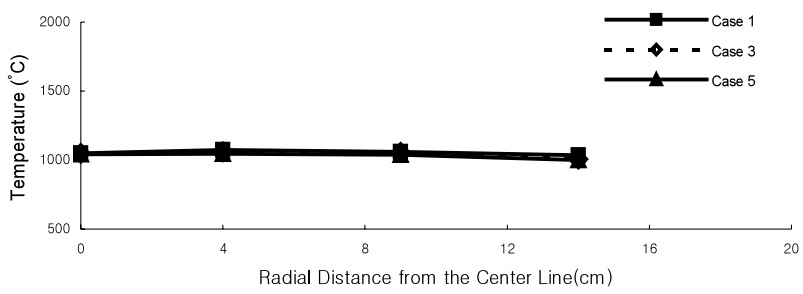

(c) $z=0.6 \mathrm{~m}$

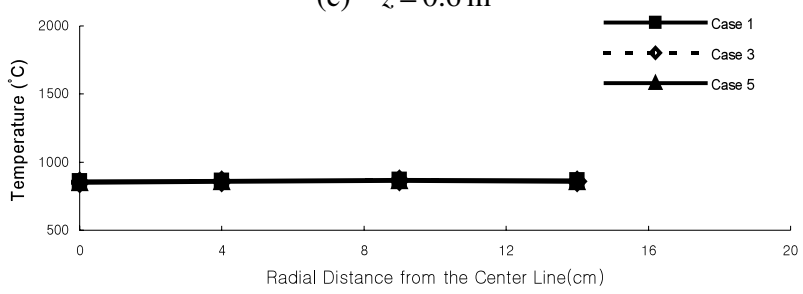

(d) $z=0.9 \mathrm{~m}$

Fig. 6 Temperature distribution along radial direction

tion. The increase of initial $\mathrm{CO}_{2}$ concentration produces lower maximum flame temperatures.

Figure 6 shows temperature distribution along the radial direction for three cases. As seen in Fig. 6(a), the maximum temperature does not occur at the centerline, but $2 \mathrm{~cm}$ away from it ax axial distance, $z=0.2 \mathrm{~m}$ from inlet. Its maximum temperature for case 1 is $1722^{\circ} \mathrm{C}$, while it decreases by 319 and $387^{\circ} \mathrm{C}$ for case 3 and 5, respectively. At $z=0.3 \mathrm{~m}$, the maximum temperature is located on the centerline again and it continuously decreases along the radial direction. At further downstream at $z=0.6$ and $0.9 \mathrm{~m}$, the radial temperature distribution becomes uniform and its temperature steadily decreases along the axial direction.

\subsection{The effect of $\mathrm{CO}_{2}$ on $\mathrm{NO}_{\mathrm{x}}$ and $\mathrm{CO}$ in case of $\Omega=0.4$}

Table 3 lists the amount of $\mathrm{NO}_{\mathrm{x}}$ formation along axial direction. As shown in table, as the amount of addition of $\mathrm{CO}_{2}$ gas increases, $\mathrm{NO}_{\mathrm{x}}$ formation is reduced, mainly because the maximum gas temperature is decreasing as explained above. Based on this observation, the $\mathrm{NO}_{\mathrm{x}}$ formed
Table $3 \mathrm{NO}_{\mathrm{x}}$ formation at the centerline (unit: $\mathrm{ppm}$ )

\begin{tabular}{|c|c|c|c|}
\hline Distance $(\mathrm{m})$ & Case 1 & Case 3 & Case 4 \\
\hline at $\mathrm{z}=0.4$ & 3021 & 1349 & 1247 \\
\hline at $\mathrm{z}=0.6$ & 3008 & 1268 & 1144 \\
\hline at $\mathrm{z}=0.8$ & 3068 & 1756 & 1178 \\
\hline
\end{tabular}

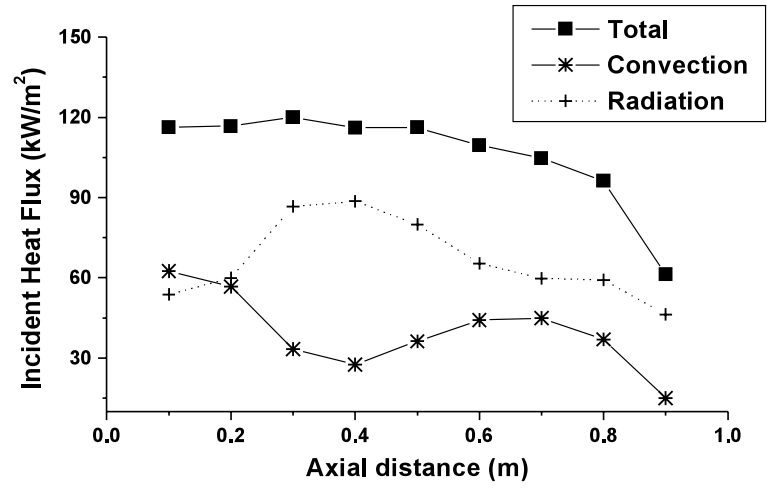

(a) Heat fluxes for Case 1

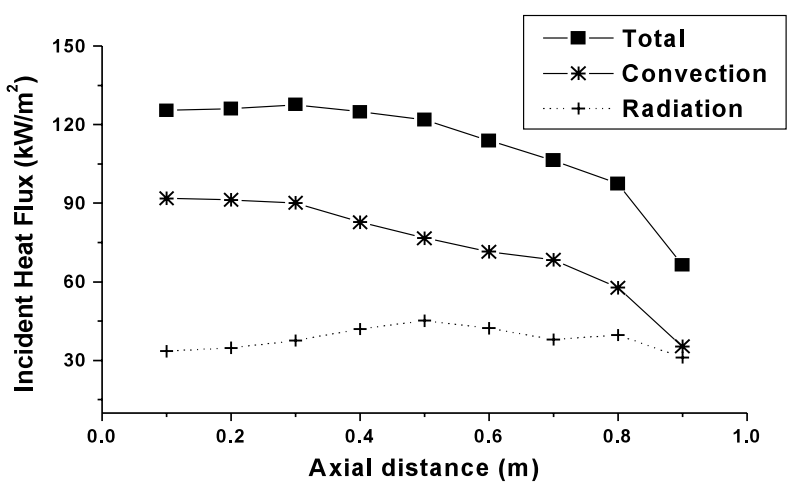

(b) Heat fluxes for Case 3

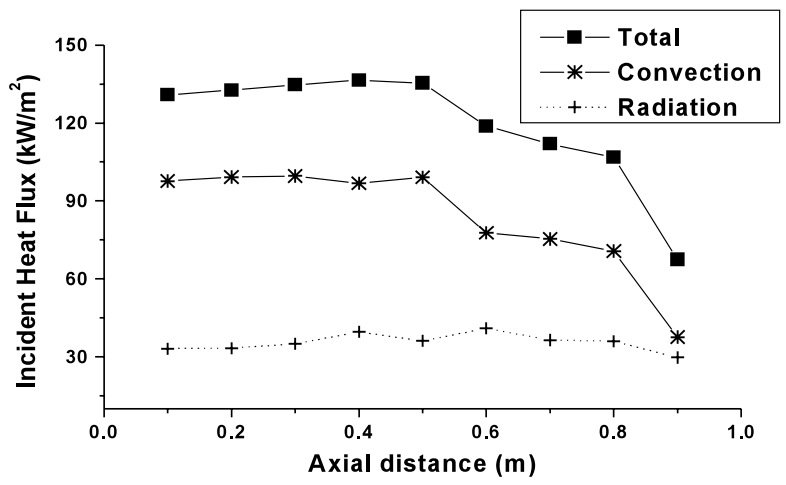

(c) Heat fluxes for Case 5

Fig. 7 Various heat fluxes to the wall for each case

in this furnace is considered to be thermally-controlled $\mathrm{NO}_{\mathrm{x}}$.

$\mathrm{CO}$ emission is also measured using a gas analyzing system of which upper limit is $15000 \mathrm{ppm}$. When $\mathrm{CO}_{2}$ was added to the flame by $20 \%$ (Case 2), CO measurement is already saturated, which indicates that it exceeds $15000 \mathrm{ppm}$. Therefore, its data is not further presented here. 


\subsection{The effect of $\mathrm{CO}_{2}$ on heat flux in case of $\Omega=0.4$}

Figure 7 shows the total as well as convective and radiative heat flux toward the wall for each case. It is found that the radiative heat flux is reduced once $\mathrm{CO}_{2}$ gas is added as shown in Fig. 7 (b) and (c) compared with Fig. 7 (a). This is considered to be due to the heat blockage effect by radiatively active $\mathrm{CO}_{2}$ gas. In other words, the $\mathrm{CO}_{2}$ gas absorbs the thermal radiation from the flame and re-emits much less. However, the convective heat flux is observed to increase as the addition of $\mathrm{CO}_{2}$ gas increases. A substitution of $\mathrm{CO}_{2}$ into $\mathrm{N}_{2}$ based on volumetric proportion actually means that more mass $\mathrm{CO}_{2}$ is added to the mixture gas by mass, since molecular weight of $\mathrm{CO}_{2}$ is bigger than that of $\mathrm{N}_{2}$. The convective heat flux is therefore, is enhanced when $\mathrm{CO}_{2}$ is added. Thereby, the total heat flux, which is a summation of convective and radiative heat fluxes, increases as the portion of $\mathrm{CO}_{2}$ increases.

For the case without $\mathrm{CO}_{2}$ addition, the convection is comparable to the radiation in upstream while the radiation becomes dominant in downstream. Therefore, the radiation plays a dominant role on average for case 1 . However, for the case with $\mathrm{CO}_{2}$ addition, the convection is dominant over the radiation in upstream, while the former becomes comparable to the latter in downstream. On average the convection is predominant over the radiation when the $\mathrm{CO}_{2}$ gas is added. Table 4 illustrates how much the total heat flux increases compared to case 1 when the $\mathrm{CO}_{2}$ gas is added. The total heat flux on average is found to increase by 5.5 and $12 \%$ for case 3 and 5 , respectively.

\subsection{The effect of $\mathrm{CO}_{2}$ on flame characteristics and $\mathrm{NO}_{\mathrm{x}}$ for case of $\boldsymbol{\Omega}=\mathbf{0 . 5}$}

Two experimental conditions are considered for the oxygen enrichment ratio of 0.5 as shown in Table 1 . One condition is without $\mathrm{CO}_{2}$ in the oxidizer (case 6), while the other has $50 \%$ of $\mathrm{CO}_{2}$ in the oxidizer instead of $\mathrm{N}_{2}$.

Even if the oxygen enrichment ratio is increased from $\Omega=0.4$ to 0.5 , it doesn't make any difference in visual flame. But still the addition of $\mathrm{CO}_{2}$ makes the flame brighter. Table 5 shows the $\mathrm{NO}_{\mathrm{x}}$ formation at the centerline for case 1 and 6 . When the oxygen enrichment ratio is $0.5, \mathrm{NO}_{\mathrm{x}}$ formation becomes more than twice as much

Table 4 Increase in total heat flux compared to Case 1 (unit: \%)

\begin{tabular}{|c|c|c|}
\hline Axial distance (m) & Case 3 & Case 5 \\
\hline 0.1 & 7.82 & 12.52 \\
\hline 0.2 & 8.05 & 13.64 \\
\hline 0.3 & 6.34 & 12.24 \\
\hline 0.4 & 7.53 & 17.50 \\
\hline 0.5 & 4.89 & 16.50 \\
\hline 0.6 & 3.90 & 8.39 \\
\hline 0.7 & 1.64 & 6.97 \\
\hline 0.8 & 1.29 & 10.99 \\
\hline 0.9 & 8.29 & 9.99 \\
\hline Average & 5.53 & 12.08 \\
\hline
\end{tabular}

as that for 0.4. This is due to the higher temperature in furnace for $\Omega=0.5$.

Likewise for the case of $\Omega=0.4$, when $\mathrm{CO}_{2}$ gas is added for $\Omega=0.5$, less $\mathrm{NO}_{\mathrm{x}}$ is detected, because $\mathrm{CO}_{2}$ gas has the effect of reduction in gas temperature.

\subsection{The effect of $\mathrm{CO}_{2}$ on heat flux for case of $\Omega=$ 0.5}

As observed in Fig. 8, it shows a similar trend as for the case of $\Omega=0.4$. When all nitrogen gas is substituted by $\mathrm{CO}_{2}$ gas on the volumetric flow, the radiative heat flux to the wall is significantly reduced while the total heat flux increases due to the enhanced convective heat flux. Because of $\mathrm{CO}_{2}$ gas added, the flame temperature is decreased while momentum influx from burner inlet is increasing.

For the case without $\mathrm{CO}_{2}$ addition (case 6), the convection is comparable to the radiation in upstream while the radiation becomes dominant in downstream, which would be very similar as before with $\Omega=0.4$. However, for the case with $\mathrm{CO}_{2}$ addition (case 7), the convection is dominant over the radiation in upstream, and the former becomes more dominant even in downstream. Therefore, for the higher oxygen enrichment ratio, the addition

Table $5 \quad \mathrm{NO}_{\mathrm{x}}$ formation at the centerline (unit: $\mathrm{ppm}$ )

\begin{tabular}{|c|c|c|}
\hline Distance $(\mathrm{m})$ & Case 1 & Case 6 \\
\hline at $\mathrm{z}=0.4$ & 3021 & 7955 \\
\hline at $\mathrm{z}=0.6$ & 3008 & $*$ \\
\hline at $\mathrm{z}=0.8$ & 3068 & $*$ \\
\hline
\end{tabular}

* represents measurement out of limit on the gas analyzer

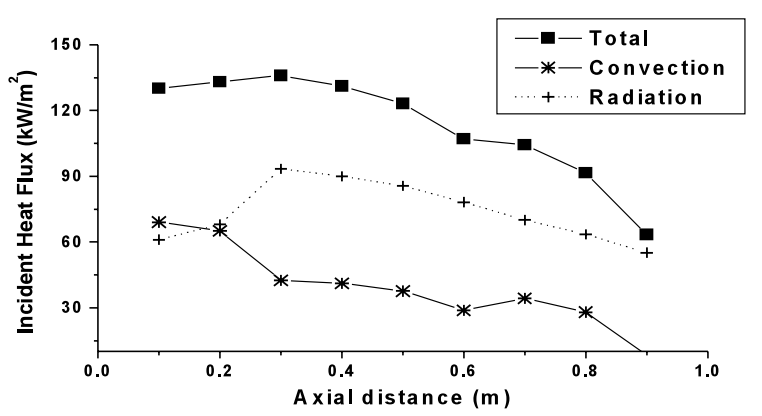

(a) Heat fluxes for Case 6

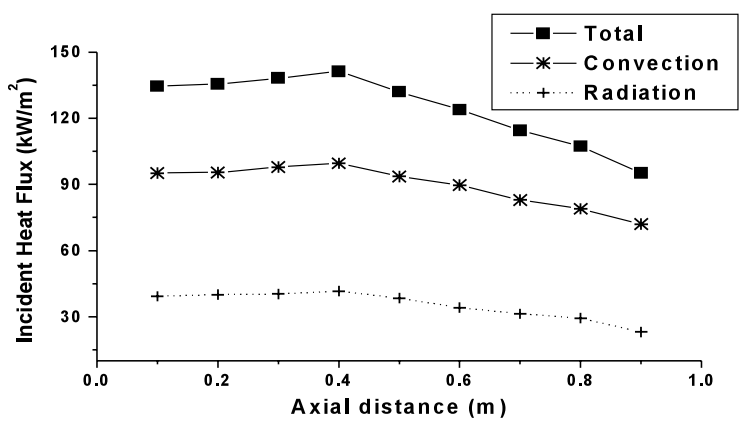

(b) Heat fluxes for Case 7

Fig. 8 Various heat fluxes to the wall for each case 
of $\mathrm{CO}_{2}$ gas further enhances the role of convection along the downstream. The total heat flux on average is found to increase by $12.7 \%$ for case 7 .

\section{Summary and Conclusions}

Experimental study was performed to examine the effect of $\mathrm{CO}_{2}$ on thermal behavior in oxygen-enriched hydrogen flame. In general, a volumetric replacement of $\mathrm{N}_{2}$ in oxidizer by $\mathrm{CO}_{2}$ gas was found to reduce flame temperature, and thereby $\mathrm{NO}_{\mathrm{x}}$ formation could be diminished. A decrease in flame temperature was attributed to the higher molar specific heat, higher heat loss to the wall and reduction in fuel consumption due to chemical effects.

For the oxygen-enhanced hydrogen combustion without addition of $\mathrm{CO}_{2}$ gas, the radiation was the dominant heat transfer mode to the wall. But as the addition of $\mathrm{CO}_{2}$ gas increased, the convection became the main heat transfer mode to the wall due to heat blockage effect in radiation, while the total heat flux increased. For the higher oxygen enrichment ratio, more $\mathrm{NO}_{\mathrm{x}}$ was produced because of even higher gas temperature.

\section{Acknowledgements}

The present work was supported by the Combustion Engineering Research Center at the Department of Mechanical Engineering, Korea Advanced Institute of Science and Technology, which is funded by the Korea Science and Engineering Foundation.

\section{References}

(1) Melvin, A., The Diffusive Combustion of Hydrogen, Hydrogen Energy Progress, Vol.2 (1980), pp.11771183.

( 2 ) Sano, H., Nakamura, T., Haruta, M., Tooyama, I. and
Souma, Y., $\mathrm{NO}_{\mathrm{x}}$ Control and Flashback Avoidance for Hydrogen Burner, Hydrogen Energy Progress, Vol.2 (1980), pp.1215-1229.

( 3 ) Suzuki, K., Maki, H. and Maesawa, M., Studies on Swirling Diffusion Flames of Hydrogen - Effect of Swirl Number and Gas Velocity on Flame Height, Hydrogen Energy Progress, Vol.2 (1980), pp.1187-1198.

(4) Baukal, C.E., Jr., Oxygen-Enhanced Combustion, (1998), CRC press, New York.

( 5 ) Baukal, C.E., and Gebhart, B., Oxygen-Enhanced/ Natural Gas Flame Radiation, Int. J. Heat Mass Transfer, Vol.40, No.11 (1997), pp.2539-2547.

(6 ) Liu, F., Guo, H., Smallwood, G.J. and Gulder, O.L., The Chemical Effects of Carbon Dioxide as an Additive in and Ethylene Diffusion Flame: Implication for Soot and $\mathrm{NO}_{\mathrm{x}}$ Formation, Combustion \& Flame, Vol.125 (2001), pp.778-787.

( 7 ) Rortveit, G.J., and Hustad, J.E., Effects of Diluents on $\mathrm{NO}_{\mathrm{x}}$ Formation in Hydrogen Counterflow Flames, Combustion \& Flame, Vol.130 (2002), pp.48-61.

( 8 ) Gupta, A.K., Lilley, D.G. and Syred, N., Swirl Flows, (1984), ABACUS PRESS, OHU.

(9) Ahn, K.Y., A Study on the Ignition and Combustion of Coal-Water Slurry Droplet, Ph.D. Thesis, Korea Advanced Institute of Science and Technology, Taejon, Korea, (1994).

(10) Stull, D.R. and Prophet, H., JANAF Thermochemical Tables - Second Edition, (1971), NSRDS.

(11) Park, J., Lee, K.M. and Lee, E., Effects of $\mathrm{CO}_{2}$ Addition on Flame Structure in Counterflow Diffusion Flame of $\mathrm{H}_{2} / \mathrm{CO}_{2} / \mathrm{N}_{2}$ Fuel, Int. J. of Energy Research, Vol.25 (2001), pp.469-485.

(12) Lee, K.M. and Park, J., A Numerical Study on Chemical Effects of $\mathrm{CO}_{2}$ Addition to Oxidizer and Fuel in $\mathrm{H}_{2}-\mathrm{O}_{2}$ Counterflow Diffusion Flames, Tran. of KSME (B), Vol.28, No.4 (2004), pp.371-381. 